\title{
CHARACTERIZATION OF HYDRATED TITANIUM OXIDE WITH SHEET-LIKE AND TUBE-LIKE STRUCTURES PREPARED BY A HYDROTHERMAL PROCESSING
}

\author{
S. FUENTES $S^{a, g}$, R.A. ZÁRATE ${ }^{b}$, R. ESPINOZA ${ }^{c}$, P. LEYTON ${ }^{d}$, D.E. DIAZ-DROGUETT ${ }^{e, f} A N D$ V.M. FUENZALIDA ${ }^{E}$ \\ aDepartamento de Química y Farmacia, Facultad de Ciencias, Universidad Católica del Norte Casilla 1280, Antofagasta, Chile. \\ ${ }^{\mathrm{b}}$ Departamento de Física, Facultad de Ciencias, Universidad Católica del Norte, Casilla 1280, Antofagasta, Chile. \\ 'Deparamento de Ciencias de Materiales FCFM, Universidad de Chile, Av. Tupper 2069, Santiago, Chile. \\ IInstituto de Química, Pontificia Universidad Católica de Valparaíso, Avenida Brasil 2950, Valparaíso, Chile. \\ 'Departamento de Física, Facultad de Ciencias Físicas y Matemáticas, Universidad de Chile, Casilla 487-3, Santiago, Chile. \\ ${ }^{f}$ Laboratorio de Ciencia de Materiales, Facultad de Física, Pontificia Universidad Católica de Chile, Av. Vicuña Mackenna 4860, Santiago, Chile. \\ ${ }^{g}$ Center for the Development of Nanoscience and Nanotechnology, CEDENNA, Santiago, Chile.
}

(Received: January 29, 2010 - Accepted: January 2, 2011)

\begin{abstract}
Hydrated titanium oxides structures have been synthesized successfully from rutile by a single-step hydrothermal process at $130^{\circ} \mathrm{C}$ in $\mathrm{NaOH}$ at concentrations of $5 \mathrm{M}$ and $10 \mathrm{M}$, monitoring up to two days. Field emission scanning electron microscopy (FEG-SEM) and transmission electron microscopy (TEM) images indicate that samples treated at $5 \mathrm{M}$ were composed of sheet-like structures, while nanotubes were mainly found at $10 \mathrm{M}$. XRD analysis for both concentrations indicated presence of two phases, hydrated titanium oxide not indexed yet and rutile. Besides, X-ray diffraction (XRD) patterns of the samples treated at $10 \mathrm{M}$ exhibited high reflections from the nanostructures, i.e., they possess high crystallinity. Thermogravimetry Analysis (TGA) indicated that the nanostructures show crystallized water in their matrix, specifically it was found that this hydrated phase has half molecule of occluded water per unit cell. This result is consistent with Raman spectroscopy that corroborates the existence of crystallization water in the synthesized product, by a deep profile of hydrated titanium oxide.
\end{abstract}

Keywords: Sheets, Tubes, Hydrothermal, Raman spectroscopy, X-ray diffraction.

\section{INTRODUCTION}

Titania and sodium titanate nanostructures have been extensively studied because of their potential application in solar cells, high performance batteries, ceramics, gas sensors, catalysis supports, photonic devices, data storage electronics, electrochemical, capacitors, inks, and paint pigments [1]. This large interest in titanium oxides is due to their unique properties, as photocatalysis. In one-dimensional structures and at nanometric scale, some properties can be magnified and new ones can appear due to quantum confinement [2].

The crystalline structure of the as-synthesized nanostructures prepared using a hydrothermal process is still unclear, despite extensive investigations using mainly anatase phase as precursor [3-6]. Rutile [7-9] as well as brookite [10] phases have been also used as precursors, but the same unclear problem about the crystalline structure was found. Lan et al. [7] argued that they used rutile as the precursor because of its higher abundance in nature in regard to anatase or brookite; industry uses this phase more often as well. They synthesized layered structures of hydrated sodium titanate from a reaction between rutile as raw material and concentrated $\mathrm{NaOH}$ solution under hydrothermal conditions. Later, the products were converted to anatase nanorods after annealing at 500 ${ }^{\circ} \mathrm{C}$. Gao et al. [8] synthesized titanium oxide nanotubes and nanorods by a hydrothermal reaction starting with rutile powder; their products exhibited a crystalline structure corresponding to hydrated protonated titanates of the form $\mathrm{H}_{2} \mathrm{Ti}_{3} \mathrm{O}_{7} \cdot 2.8 \mathrm{H}_{2} \mathrm{O}$, result obtained by TGA. On the other hand, Thorne et al. [9] performed a study of the variation of the hydrothermal synthesis conditions and post treatments; they reported the growth of nanotubes of hydrogenated titanates rather than titania, these structures decomposed in anatase by dehydration below $300^{\circ} \mathrm{C}$. In Thorne's work, the nanotubes presented sharp diffraction lines and Raman shifts, which indicated the high crystallinity of the samples. This fact had not been reported in previous literature devoted to the synthesis of titania derived nanotubes via wet chemical reactions utilizing anatase, rutile and brookite as precursors.

In this article, we present the study of the growth of hydrated titanium oxide nanotubes obtained from a hydrothermal process using rutile as precursor. The properties of the nanotubes have been carefully analyzed by several characterization techniques. Specifically, the water crystallization was evidenced by Raman spectroscopy and Thermogravimetry analysis.

\section{EXPERIMENTAL PROCEDURE}

The sodium titanate nanotubes were hydrothermally synthesized in a Teflon beaker containing $25 \mathrm{ml} \mathrm{NaOH}$ (Aldrich, 99.99\%) at concentrations of 5 and $10 \mathrm{M}$, placed in a sealed reactor together with $0.21 \mathrm{~g}$ of $\mathrm{TiO}_{2}$ (rutile from Aldrich, 99.8\%). The resulting solution was stirred for $1 \mathrm{~h}$ at room temperature. The mixture was then heated at $130{ }^{\circ} \mathrm{C}$ and treated during 12 , 18,24 and $48 \mathrm{~h}$. The obtained powders were washed with $0.1 \mathrm{M} \mathrm{HCl}$ aqueous solution and distilled water and were subsequently separated from the solution by centrifugation. This operation was repeated until the washing water showed a $\mathrm{pH}$ less than 7.

The XDR data were recorded on using a Siemens D5000 powder diffractometer with $\mathrm{CuK} \alpha$ radiation $(40 \mathrm{kV}, 30 \mathrm{~mA})$. The Raman spectra were recording out on a WITEC model CRC200 using a $5.5 \mathrm{~mW}$ laser with a wavelength of $514.5 \mathrm{~nm}$. The AFM images were taken by the same equipment. The morphology of the powder materials was observed by a field emission scanning electron microscope (FEG-SEM JSM-6330F), and a low vacuum scanning electron microscope (LV-SEM, JSM-5900LV), equipped with a $\mathrm{X}$-ray microanalysis detector, used to obtain EDX spectra. High-resolution images were obtained using a FEI Tecnai STwin F20 FEG transmission electron microscope (TEM). The TEM samples were prepared by suspending the powder in ethanol and then collecting it using a carbon grid.

\section{RESULTS AND DISCUSSION}

\subsection{Morphology}

The starting rutile material consisted of spherical particles, and of particles with very well defined faces; the sizes oscillated between $100 \mathrm{~nm}$ and $3 \mu \mathrm{m}$. An image of the raw material is not included in this work but the morphology is similar to that shown in Figure 1a. After the hydrothermal treatment in $\mathrm{NaOH}$ $5 \mathrm{M}$, the formation of sheet-like structures is evidenced in of Figure 1. Each particle of rutile is exfoliated in isolated sheets and the coalescence of them gives rise to the larger sheets, which reach widths from 10 to $100 \mathrm{~nm}$ and lengths of several $\mu \mathrm{m}$ (Figure 1a and 1b). 

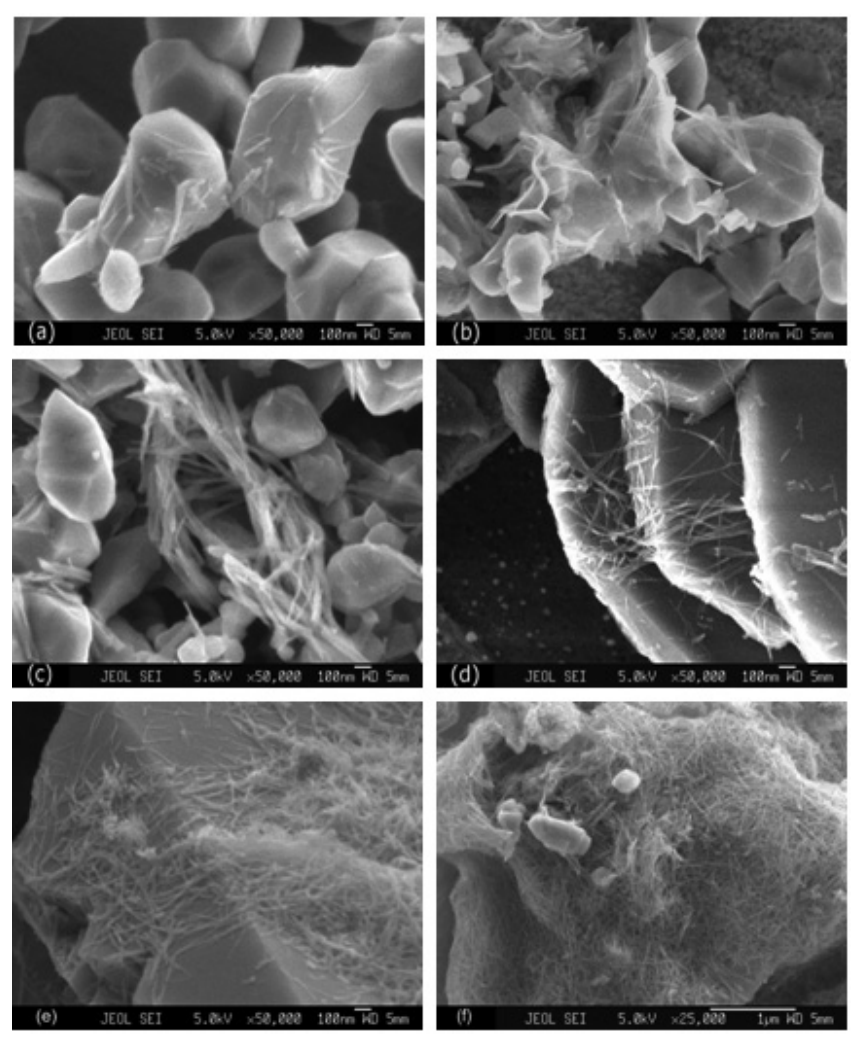

Figure 1. FEG-SEM images of hydrothermal samples treated at (a) 1D $5 \mathrm{M}, \mathrm{b}$ ) and (c) $2 \mathrm{D} 5 \mathrm{M},(\mathrm{d}) 12 \mathrm{~h} 10 \mathrm{M}$ and (e) and (f) $1 \mathrm{D} 10 \mathrm{M}$.

It is well known that the surface strengths on the sheets give initial point to the formation of nanotubes by rolling up of sheets into tubes, this process seems to be very fast, which was proved by a computer simulation [11], therefore it is rare to observe sheet-like structures [11]. Ma et al. [12] proposed a controlled procedure to intentionally roll sheets into tubes directly.

In our case, the process of formation for converting sheets into tubes is relatively slow in a solution $5 \mathrm{M} \mathrm{NaOH}$. After two days of reaction the samples are mainly composed of sheet-like structures of different sizes, some of them are already curved, as shown in Figure $1 \mathrm{~b}$ and $1 \mathrm{c}$. The morphology of the hydrothermal samples at $10 \mathrm{M}$ showed the presence of cylindrical structures with diameters from 10 to $30 \mathrm{~nm}$ and lengths from $500 \mathrm{~nm}$ up to several $\mu \mathrm{m}$, as shown in Figures 1d, 1e and 1f. Treatments of $12 \mathrm{~h}$ of reaction presented morphology composed of cylindrical-like and a few sheet-like structures with large pieces of the unreacted precursor were still present, as depicted in Figure $1 \mathrm{~d}$.

For samples after $24 \mathrm{~h}$ of reaction, the morphology was composed of cylindrical-like structures and large pieces corresponding to unreacted precursor, i.e., the transformation from spherical particles into cylindricallike structures is not complete, as shown in Figures 1e. In other zones of the same sample after $24 \mathrm{~h}$ of reaction, the morphology was dominated by cylindrical structures (see Figure 1f). In contrast, the product obtained after 24 $\mathrm{h}$ of reaction in a concentration of $5 \mathrm{M}$ mainly exhibited spherical particles. Therefore as already evidenced, the increase of the exfoliation rate depends on the reaction time and of the $\mathrm{NaOH}$ concentration.

In summary, the observations performed by FEG-SEM indicated that hydrothermal reaction at $5 \mathrm{M}$ produce only sheet-like structures up to two days of reaction. Besides, the transformation from spherical particles into nanotubes is not complete in both solutions $5 \mathrm{M}$ and $10 \mathrm{M} \mathrm{NaOH}$. A plausible explanation is that rutile is the most stable crystalline phase of all polymorphic forms of titanium dioxides.

\subsection{Compositional Analysis}

X-ray photoelectron spectroscopy (XPS) and energy dispersive X-ray spectroscopy (EDX) were used to detect the sodium content of the hydrated titanium oxide compounds. The XPS spectra of the products treated in a concentration of $5 \mathrm{M}$ and $10 \mathrm{M}$ revealed the presence of titanium and oxygen, where the sodium content was found to trace level on the surface. Figure 2a shows high-resolution spectra in the Na1s line, which confirmed that the samples contained sodium in their matrix at trace levels, below 0.5 at.\%. The atomic percentages of the elements on the surface of the samples are about $77 \%$ for $\mathrm{O} 1 \mathrm{~s}, 22 \%$ for $\mathrm{Ti} 2 \mathrm{p} 3 / 2$, and the ratio $\mathrm{O} 1 \mathrm{~s} / \mathrm{Ti} 2 \mathrm{p}$ is about 3.5 . Therefore, this sample has excess of oxygen and deficiency of titanium on its surface with respect to a pure $\mathrm{TiO}_{2}$ sample. In parallel, EDX was used to study the sodium content in the bulk of the sample, to compare with XPS which is a surface analysis technique. The EDX spectra for samples prepared at $5 \mathrm{M}$ and $10 \mathrm{M}$ exhibited similar atomic percentages of titanium in the $\operatorname{Ti}(\mathrm{K})$ line and oxygen in the $\mathrm{O}(\mathrm{K})$ line. Figure $2 \mathrm{~b}$ shows an EDX spectrum of a sample prepared at $10 \mathrm{M}$ and $24 \mathrm{~h}$ of reaction, which presented the following atomic percentages: $34.7 \%$ in the $\mathrm{Ti}(\mathrm{K})$ line, $65.0 \%$ in the $\mathrm{O}(\mathrm{K})$ line and about $0.3 \%$ in the $\mathrm{Na}(\mathrm{K})$ line. In this case, the ratio $\mathrm{O}(\mathrm{K}) / \mathrm{Ti}(\mathrm{K})$ for this sample is about 1.87 , therefore the stoichiometry approximately corresponds to the $\mathrm{TiO}_{2}$, with slight defficiency in oxygen and rich in titanium. In conclusion, the oxygen atomic percentage could screen the others elements which explain the difference in percentages in EDX and XPS.
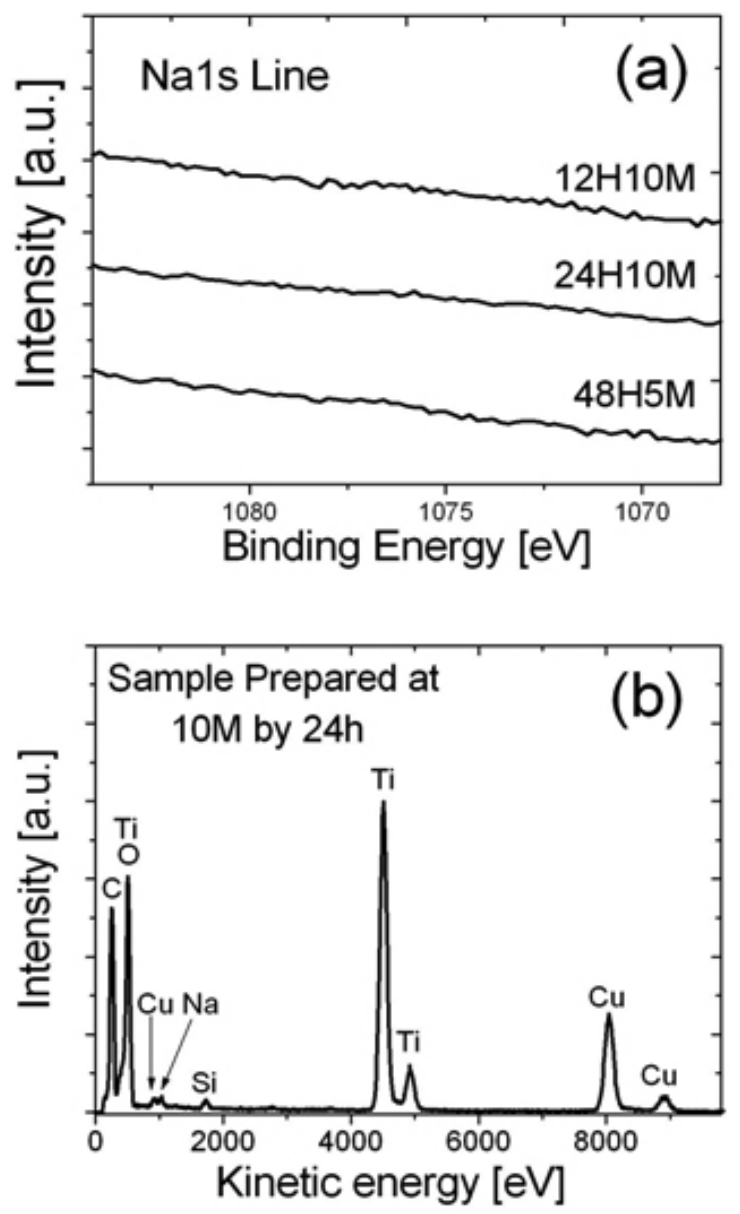

Figure 2. (a) High resolution XPS spectra in the Na1s line of three samples treated at different concentrations and reaction time and (b) EDX spectrum of a sample prepared from rutile precursor during $24 \mathrm{hrs}$ at $10 \mathrm{M}$.

\subsection{Thermogravimetry Analysis}

Thermogravimetry analysis was used to study the existence of occluded water in the hydrothermal samples. TGA thermogram shown in Figure 3 was only taken to the sample prepared at $10 \mathrm{M}$ and $24 \mathrm{~h}$ of reaction, because this presented the highest conversion rate from rutile to the hydrated phase. The limit between adsorbed and crystallization water is not clear, but in general, it is assumed that for temperatures lower than $150{ }^{\circ} \mathrm{C}$, the water is physically absorbed [13]. 
The peak bellow $120^{\circ} \mathrm{C}$ is indicating the elimination of the absorbed water. The loss of weight at temperatures higher than $200{ }^{\circ} \mathrm{C}$ mainly comes from crystallization water. From Figure 3, the loss weight about 3\% corresponds to water physically adsorbed on the sample, where the limit is indicated by a dash line at $150^{\circ} \mathrm{C}$. There are two other important weight losses about 200 and 300 ${ }^{\circ} \mathrm{C}$, that correspond to a loss of $2.4 \mathrm{wt} . \%$ and 2.8 wt. \%, respectively. They can be attributed to water molecularly absorbed as crystallized water.

The total weight loss was about $9.0 \%$ and it occurred between 50 and 350 ${ }^{\circ} \mathrm{C}$. If we assume that the sample is composed of titanium dioxide in one of its phases, the occluded water by unit cell of $\mathrm{TiO}_{2}$ corresponds to half water molecule by unit cell, i.e., the new phase occurs as hydrated titanium oxide. A similar result has been informed by Suda et al. [14]. Other researchers have informed that their as-synthesized samples are present as titanium dioxide hydrate phases of the form $\mathrm{TiO}_{2} \cdot 1.25 \mathrm{H}_{2} \mathrm{O}$ and $\mathrm{TiO}_{2} \cdot \mathrm{H}_{2} \mathrm{O}$ for nanotubes and nanorods, respectively [7]. On the other hand, in the literature there are reports where their as-synthesized samples occurs as protonated titanate hydrate, specifically as trititanate in the phase $\mathrm{H}_{2} \mathrm{Ti}_{3} \mathrm{O}_{7} \cdot 2.8 \mathrm{H}_{2} \mathrm{O}[8]$ and in the phase $\mathrm{H}_{2} \mathrm{Ti}_{3} \mathrm{O}_{7} \cdot 0.8 \mathrm{H}_{2} \mathrm{O}[9]$.

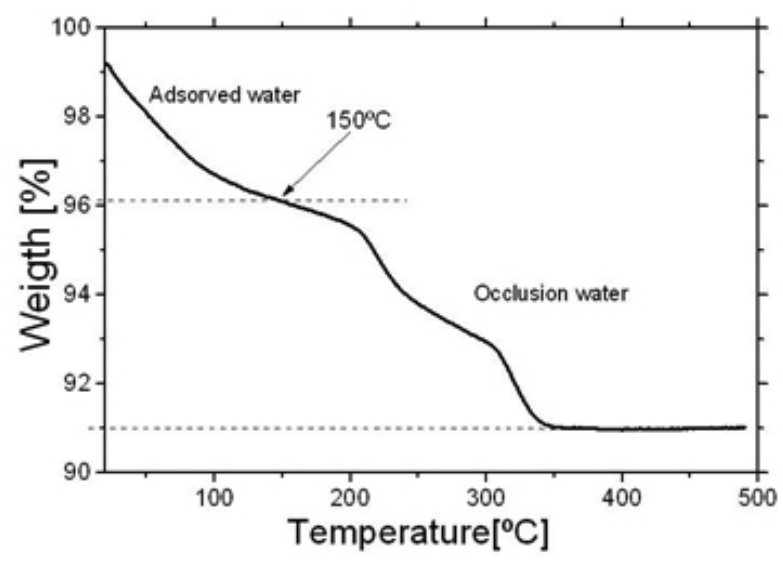

Figure 3. TGA spectrum of a sample prepared during $24 \mathrm{~h}$ at $130^{\circ} \mathrm{C}$ in a concentration of $10 \mathrm{M} \mathrm{NaOH}$.

\subsection{Structural analysis. XRD}

The diffractograms of all samples prepared in this work are similar, i.e., they mainly present reflections from the precursor and hydrated crystallographic phases, which to the best of our knowledge, have not been yet been indexed. The samples treated in a concentration of $5 \mathrm{M} \mathrm{NaOH}$ exhibited diffraction lines of rutile $(\mathrm{R})$ mixed with anatase $(\mathrm{A})$ and the hydrated phase $(\mathrm{T})$. However, the hydrated phase has reflections of low intensity in comparison to the precursor, i.e., the sheet-like structures have low crystallinity, as shown in Figure 4a. After treatment with $10 \mathrm{M} \mathrm{NaOH}$, the diffractograms exhibited sharp diffraction lines of rutile and of hydrated phase (T), but not from anatase (Figure $4 \mathrm{~b}$ ). In this case, the hydrated phase exhibited diffraction lines as intense as the rutile phase, which indicates that the cylindrical-like structures have higher cristallinity than the sheet-like structures obtained at $5 \mathrm{M}$. Contrarily to our case, it is well known in literature that the as-synthesized nanostructures, grown by hydrothermal processes and using anatase as precursor, exhibit XRD patterns with very low intensity diffraction lines [5-6, 17].

Several research groups working on titanium-derived nanostructures have utilized rutile as precursor. Although their products have been synthesized under similar hydrothermal conditions, the crystalline phases found by them are clearly different to the phases found in this work [7-9]. Moreover, our samples presented intense diffraction lines, which are comparable to the intensity of rutile phase. It is well-known that rutile and anatase have a high cross section in Raman microscopy and XRD techniques in comparison with other oxides like, for example, copper oxides. This fact has not been reported in the literature devoted to the synthesis of titania derived nanotubes via wet chemical reactions, using the titania as precursor in all their phases: anatase, rutile and brookite.
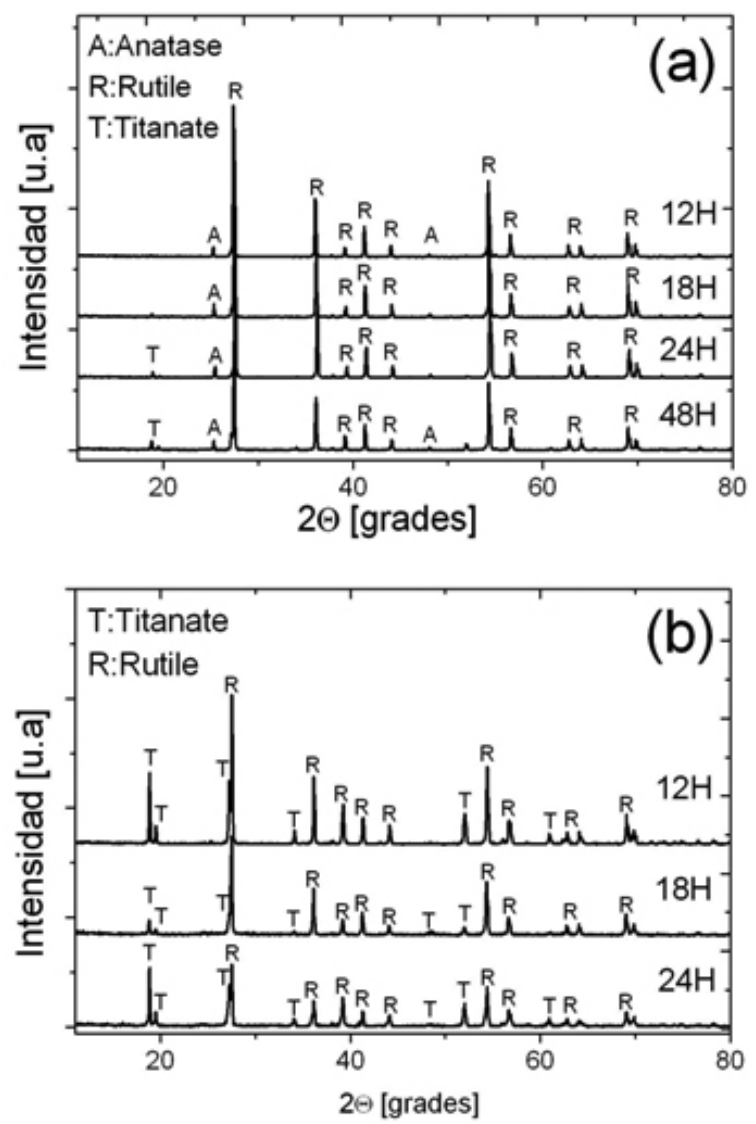

Figure 4. XRD patterns of samples prepared (a) at $5 \mathrm{M}$ and (b) $10 \mathrm{M}$ at various reaction times.

\subsection{Structural properties by TEM and SAED}

In the Figure 5a shows a low magnification TEM image of a sample prepared by a hydrothermal process in a concentration of $10 \mathrm{M} \mathrm{NaOH}$ after $24 \mathrm{~h}$ of reaction. This image shows nanotubes of hydrated titanium oxide with diameters between $10 \mathrm{~nm}$ and $20 \mathrm{~nm}$ and lengths from $500 \mathrm{~nm}$ up to several $\mu \mathrm{m}$. First, selective area electron diffraction (SAED) was used to calculate the crystalline planes of the hydrated phase. The electron diffraction pattern shown in the top inset of Figure 5a was obtained in a large area containing several nanotubes. From the radii of the rings observed in the diffraction pattern the distances of crystalline planes were calculated, with results of $0.37,0.19$, $0.15,0.13$, and $0.1 \mathrm{~nm}$, respectively. Second, to confirm the crystalline planes previously found, the fringes distances of the nanotubes shown in the TEM image of Figure $5 \mathrm{~b}$ were measured, with results of $0.36,0.32,0.19$ and 0.15 $\mathrm{nm}$, respectively. The top inset of Figure $5 \mathrm{~b}$ is a high resolution (HR) TEM image, which shows a layered structure.

There is no complete correspondence between interplanar distances obtained from HRTEM images and the crystalline planes obtained from the electron diffraction patterns, i.e., interplanar distance about $0.32-0.33 \mathrm{~nm}$ were not found by electron diffraction. Moreover, both results previously found do not correspond to the crystalline planes obtained from the XRD patterns. We speculate that the difference could be due to the occlusion water in the samples, which have modified the intershell distances increasing the values presented by rutile [12]. The crystalline planes obtained from XRD patterns are not modified by the radiation that comes from $\mathrm{CuK \alpha}$ line, due to the fact that the energy of this ray is not enough for inducing the water desorption. However, the electron beam of the TEM at $200 \mathrm{keV}$ induce desorption of the occluded water. 

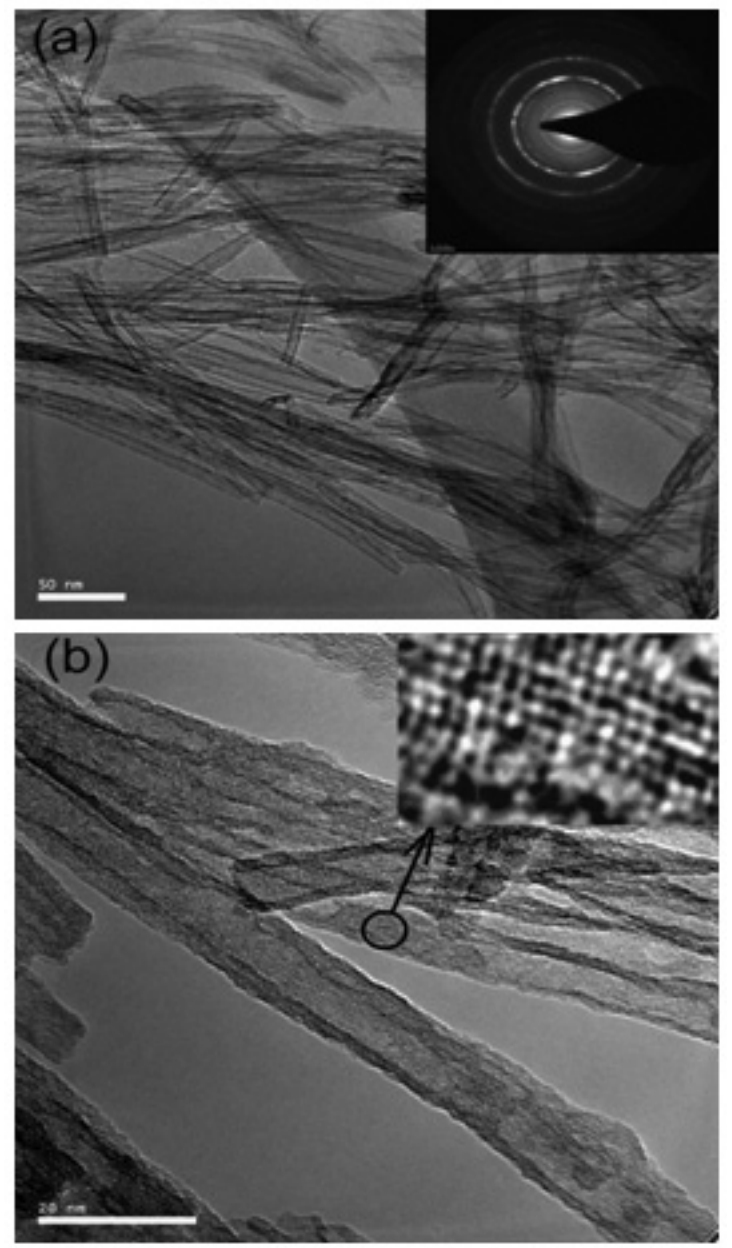

Figure 5. (a) Low magnification TEM image. Top inset is their electron diffraction pattern and (b) TEM image and their HRTEM image in the top inset. Both hydrothermal samples were prepared at $10 \mathrm{M}$ by $24 \mathrm{~h}$ of reaction.

Such controversies have been also evidenced by others researchers, when their electron diffraction patterns for nanotubes and nanorods do not match with XRD results [12]. It was confirmed that the crystalline planes obtained by electron diffraction do not correspond with neither anatase nor rutile or any other compound previously reported [17]. In conclusion, the fringes should have smaller distances than those of the crystalline planes revealed by XRD Although the distance of the $\mathrm{H}-\mathrm{O}$ bond is about $0.097 \mathrm{~nm}$, the crystalline planes of the rutile will be modified depending on the crystal structure formed.

\subsection{Raman Spectroscopy}

Raman spectroscopy was used in order to study the vibration modes of hydrothermal samples. The result presented in this work corresponds to a sample prepared at $130{ }^{\circ} \mathrm{C}$ in a concentration of $10 \mathrm{M} \mathrm{NaOH}$ after $24 \mathrm{~h}$ of reaction. It was chosen, because this sample presented the more intense vibrational bands, as shown in Figure 6. It is well known that Raman spectroscopy can detect all polymorphic phases of $\mathrm{TiO}_{2}$ and the assignment of bands to rutile, anatase, brookite and $\mathrm{TiO}_{2}-\mathrm{B}$ have been previously reported [15-16]. Anatase, brookite and $\mathrm{TiO}_{2}-\mathrm{B}$ are not thermodynamically stable and they can transform irreversibly and exothermically into rutile when they are heated to high temperatures [16].

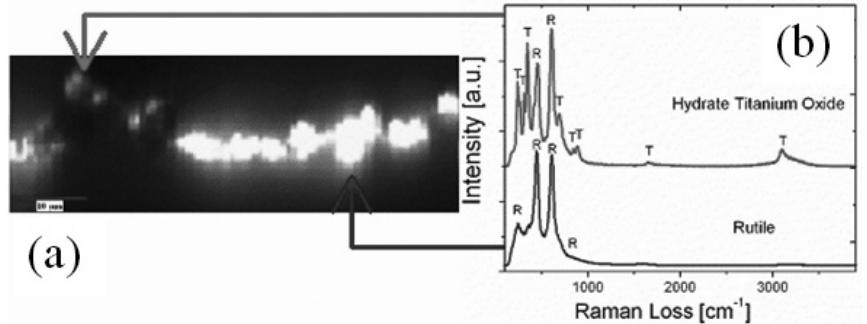

Figure 6. (a) Raman Deep profile and (b) Raman shifts of hydrothermal samples treated at $10 \mathrm{M}$ and $24 \mathrm{~h}$ of processing.

The Raman depth profile markedly exhibited two zones of different grey tones (Figure 6a). The brilliant zone corresponds to the rutile phase (R) and their typical Raman spectrum is shown in the bottom curve of Figure 6b. On the other hand, the grey dark zone corresponds to the hydrated phase (T), which is mixed with rutile, as it is shown in the top spectrum of Figure 6b. The latter spectrum reveals interesting differences in relation to the rutile Raman shifts. The vibrational bands of this sample are localized at 243, 266, 313, 349, $458,691,844,888 \mathrm{~cm}^{-1}$. However, similar Raman spectrum was not found in literature or data bases, despite an exhaustive search about. Besides, it was confirmed that these vibrational bands correspond to the hydrated material, because the laser beam does not have enough energy to cause water desorption.

Finally, we also found characteristic weak bands at 1657 and 3102 $\mathrm{cm}^{-1}$ attributed to the stretching vibration of $\mathrm{OH}$ groups, probably due to crystallization water and to the bending vibration of molecular $\mathrm{H}_{2} \mathrm{O}$, respectively. These results are supported by Thermogravimetry Analysis (TGA) and corroborate the existence of crystallization water in as-synthesised samples. It was also found that their empirical formulation corresponds to $\mathrm{TiO}_{2} \cdot 1 / 2 \mathrm{H}_{2} \mathrm{O}$.

\section{CONCLUSIONS}

Hydrated titanium oxides with sheet-like and tube-like structures have been successfully synthesized from rutile as precursor by a single-step hydrothermal process at $130{ }^{\circ} \mathrm{C}$ in a $\mathrm{NaOH}$ concentration of $5 \mathrm{M}$ and $10 \mathrm{M}$, respectively.

It was proven that the samples synthesized at $5 \mathrm{M}$ are mainly composed by sheet-like structures. They were found in samples with up to 2 days of reaction, which constitutes a controversy with the literature. XRD and Raman spectroscopy clearly revealed two crystalline phases in both concentrations with the highest crystallinity of the nanostructures found for samples prepared at 10 M. Although the intensity of rutile lines appeared lowered in approximately a factor of four with respect to the lines of the unreacted rutile, it is unusual to find sharp diffraction lines corresponding to the nanostructures in as-prepared samples for syntheses at moderate temperatures as $130{ }^{\circ} \mathrm{C}$.

The crystalline phase obtained in this work corresponding to the sheetlike and tube-like structures had not been informed and neither indexed yet. Besides, fringes spaces of the tubes obtained from HRTEM images and lattice distances found by electron diffraction (SAED) of nanotubes do not agree with those found by $\mathrm{XRD}$, due to the occlusion water in the rutile matrix which increases the lattice parameters. Also, inside of the TEM this water is desorbed from nanostructures by exposition of them to the electron beam of $200 \mathrm{kV}$. The existence of the crystallized water was proved by Raman microscopy, which was detected at 1657 and $3102 \mathrm{~cm}^{-1}$. Thermogravimetry analysis confirmed the existence of the occlusion water and permitted to calculate that each unit cell contains half molecule of water.

\section{ACKNOWLEDGEMENTS}

The authors wish to thank to the FONDECYT grant under the contract $\mathrm{N}^{\circ} 1110555$. We acknowledge to FUNDACIÓN ANDES for their support to Experimental Physics under the grant number C-13876. Basal Financing Program CONICYT, FB0807 (CEDENNA), Millenium Science Nucleus P06022-F.

\section{REFERENCES}

1. G. Patzke, F. Krumeich and R. Nesper, Angew. Chem. Int. 41(2002) 2446.

2. R. Saito, M. Fujita, G. Dresselhaus and M. Dreselhaus, Physical Properties of Carbon Nanotubes, Imperial College Press, 1998. 
3. G. Du, Q. Chen, R. Che, Z. Yuan, L. Peng, App. Phys. Lett. 79-22 (2001) 3702 .

4. C. Tsai and H. Teng, Chem. Matt. 18 (2006) 367.

5. Y. Suzuki and S. Yoshikawa, J. Mater. Res. 19-4 (2004) 982.

6. B. Poudel, W. Wang, C. Dames, J. Huang, S. Kunwar, D. Wang, D. Banerjee, G. Chen, and Z. Ren, Nanotechnology. 16 (2005) 1935.

7. Y. Lan, X. Gao, H. Zhu, Z. Zheng, T. Yan, F. Wu, S. Ringer and D. Song, Adv. Funct. Mater. 15 (2005) 1310.

8. X. P. Gao, Y. Lan, H. Zhu, J. Liu, Y. Ge, F. Wu and D. Song. Electrochemical and Solid-State Letter. 8-1 (2005) A26.

9. A. Thorne, Angela Kruth, D. Tunstall, J. Irvine, and W. Zhou, J. Phys. Chem. 109 (2005) 5439.

10. X. Meng, D. Wang, J. Liu, S. Zhang, Mater. Res. Bull. 39 (2004) 2163.
11. S. Zhang, L. Peng, Q. Chen, G. Du, G. Dawson, W. Zhou, Phys. Rev. Lett. 91 (2003) 256103.

12. R. Ma, Y. Bando and T. Sasaki, J. Phys. Chem. B. 108 (2004) 2115.

13. Z. Zhang, P. A. Maggard, Journal of Photochemistry and Photobiology A: Chemistry. 186 (2007) 8.

14. Y. Suda and T. Morimoto, Langmuir. 3 (1987) 786.

15. Y. Zhang, C. Chan, J. Porter and W. Guo, J. Mater. Res. 13 (1998) 2602.

16. Y. Kolenko, K. Kovnir, A. Gavrilov, A. Garshev, J. Frantti, O. Lebedev, B. Churagulov, G. Tendeloo, and M. Yoshimura, J. Phys. Chem. B 110 (2006) 4030.

17. R.A. Zárate, S Fuentes, J.P. Wiff, V.M Fuenzalida, and A. L. Cabrera, J. Phys. Chem. Solids. 68 (2007) 628. 